\title{
Early treatment of juvenile xanthogranuloma of the iris with subconjunctival steroids
}

\author{
I Casteels, J Olver, M Malone, D Taylor
}

\begin{abstract}
Five infants with biopsy proved juvenile xanthogranuloma of the iris were reviewed. Early treatment with subconjunctival injection of steroids and topical steroid drops resulted in regression of the lesion in four patients. One patient, reviewed at the age of 8 months after glaucoma which had developed secondary to the iris xanthogranuloma, had been treated by surgery alone: the visual outcome was very poor.

(Br F Ophthalmol 1993; 77: 57-60)
\end{abstract}

Juvenile xanthogranuloma is a rare disorder of infants and very young children of unknown aetiology. It has a tendency to affect the ocular structures and particularly the iris. The ocular involvement was first recognised in 1949 and was described by Blank et al. ${ }^{1}$ The first case published in the ophthalmic literature was by Maumenee in 1956.

Early diagnosis and treatment of ocular involvement determine the final visual outcome.

\section{Case reports}

CASE 1

This patient was referred at the age of 8 months. At 8 weeks of age a few yellowish skin lesions were noted which increased in number over the next month. A dermatologist performed a skin biopsy and the diagnosis of a juvenile xanthogranuloma was made. At about the same time a hyphaema was noted in the right eye. Treatment with topical steroids five times a day was initiated. Five other hyphaemas developed over the next months with cloudiness of the cornea.

On examination the child fixed and followed well with each eye. The right pupil was oval but reacted well. The iris was infiltrated and highly vascularised. An examination under anaesthesia revealed equal corneal diameters in both eyes and normal intraocular pressures. There was a greyyellow mass in the inferior periphery of the iris and prominent iris vessels were present. Because the diagnosis had already been made by skin biopsy, an iris biopsy or paracentesis of the aqueous was not performed. Methylprednisolone, $30 \mathrm{mg}$ was injected subconjunctivally adjacent to the lesion and the child was sent home on $0 \cdot 1 \%$ dexamethasone drops six times a day for 1 month. There has been no hyphaema over the last 8 months and the iris mass has disappeared. The left eye is patched 1 hour a day. The skin lesions also resolved spontaneously.
CASE 2

At 7 months this boy became very photophobic and the right eye was noted to be bloodshot and watering. On examination an extensive vascularised mass of the right iris and a hyphaema were noted. No typical skin lesions could be observed. An examination under anaesthesia revealed intraocular pressures of $20 \mathrm{~mm} \mathrm{Hg}$ on the right and $9 \mathrm{~mm} \mathrm{Hg}$ on the left. There was a very friable, pale, and highly vascularised iris mass extending temporally to the pupillary margin. An aqueous tap and an iris biopsy were taken and $30 \mathrm{mg}$ of methylprednisolone were injected subconjunctivally. Afterwards he was treated with $0 \cdot 1 \%$ dexamethasone drops six times a day. Postoperatively he developed a hyphaema which cleared over 7 days. Histopathological examination of the iris biopsy showed an infiltrate of bland histiocytes indicating a juvenile xanthogranuloma (Fig 1). Two months later another examination under anaesthesia revealed normal intraocular pressures and marked regression of the lesion. The subconjunctival steroid injection was repeated and $0.1 \%$ dexamethasone drops were continued for another month. The lesion was found to have regressed completely at an examination after 3 and 7 months. With Keeler acuity cards vision was found to be equal.

\section{CASE 3}

This boy was referred at the age of 8 months. For 2 months he had had a watering left eye followed by a discoloration of the left iris. The mother also noticed the eye was bloodshot from time to time. No skin lesions were observed. He was very photophobic.

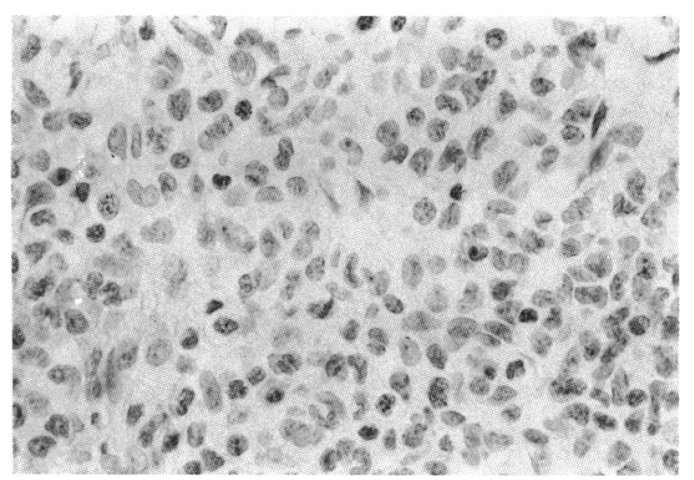

Figure 1 Iris biopsy showing an infiltrate of bland histiocytes. There are no features to suggest malignancy, and the appearances are compatible with juvenile xanthogranuloma. Haematoxylin and eosin, $\times 127$. 


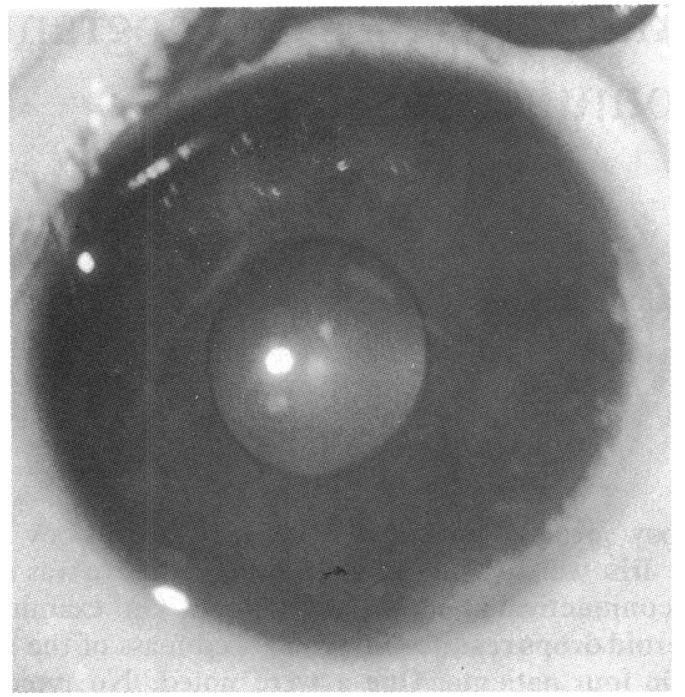

Figure 2 The left pupil was irregular and inferiorly there was a white iris mass in the anterior chamber.

The left pupil was irregular, and there was a white mass in the left anterior chamber (Fig 2). On retinoscopy the left eye was markedly myopic. Fundi in both eyes were normal. On examination under anaesthesia intraocular pressures were normal. A biopsy of the iris and an aqueous tap were sent for histopathological examination. Methylprednisolone, $30 \mathrm{mg}$, was injected subconjunctivally adjacent to the lesion, and the child was sent home on $0.1 \%$ dexamethasone drops six times a day. Histopathology of the anterior chamber aspirate revealed a juvenile xanthogranuloma (Fig 3). We reviewed him after 1 week; there was still a residual xanthogranuloma. Another examination under anaesthesia was carried out with subconjunctival injection of $30 \mathrm{mg}$ methylprednisolone after 1 and 2 months. The eye cleared, and occlusion therapy was started because of anisometropia.

\section{CASE 4}

A girl of 4 months was referred. At 3 months the mother had noticed that the right eye had changed colour from blue to green-brown. The eye was also bloodshot and watering. Over the next week a hyphaema developed. On examination the patient was very photophobic and the iris was diffusely infiltrated. An examination under anaesthesia was performed in the local hospital.

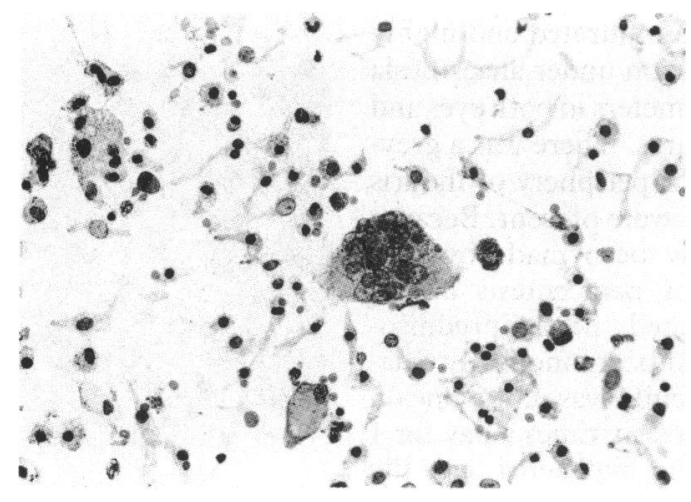

Figure 3 Anterior chamber aspirate showing numerous foamy macrophages with bland nuclear cytology. Note the multinucleated giant cell. Haematoxylin and eosin, $\times 50$.
Intraocular pressures were normal. The right iris was diffusely infiltrated and highly vascularised and there was a hyphaema in the anterior chamber. Fundi were normal in both eyes. She had been treated with $0 \cdot 1 \%$ dexamethasone drops four times a day. We reviewed the child 1 month later. The right eye was very photophobic, the cornea was slightly cloudy, and a hyphaema was still present. No skin lesions could be detected. The next day the child was examined under anaesthesia with biopsy of the iris and an aqueous tap. Methylprednisolone, $30 \mathrm{mg}$, was injected subconjunctivally and the patient was sent home on $0 \cdot 1 \%$ dexamethasone drops six times a day and betaxolol drops twice a day. Histopathological examination of the anterior chamber fluid and the iris revealed a juvenile xanthogranuloma. The child was reviewed 2 weeks later. She was much less photophobic, there was only a small remnant of a hyphaema, and a slightly cloudy cornea. Another examination under anaesthesia 1 month later revealed normal intraocular pressures, a clear cornea, and a much less infiltrated iris. Methylprednisolone, $30 \mathrm{mg}$, was injected subconjunctivally and she was discharged on $0.1 \%$ dexamethasone drops six times a day and betaxolol drops twice a day. Patching of the left eye for 30 minutes a day was started. The lesion cleared and no further hyphaema appeared.

CASE 5

At the age of 1 week this boy was noticed to have a hazy left cornea with high intraocular pressure. At 4 weeks a trabeculectomy was performed on this eye. Shortly afterwards he developed a sudden eruption of typical yellowish lesions over his body. Biopsy of the skin lesions confirmed the diagnosis of juvenile xanthogranuloma. As the intraocular pressure on the right was raised, two antiglaucomatous operations were performed. The child was referred to us at 8 months of age. There was only light perception. On examination under anaesthesia the eyes were found to be large with a horizontal diameter of about $14.5 \mathrm{~mm}$ and an ill defined limbus.

Fibreoptic transillumination showed that the posterior surface of the cornea was covered with pigment, presumably derived from the iris during the trabeculectomy procedures. There were also trabeculated aręas of yellowish infiltration in the cornea. Intraocular pressures were normal. The fundi could not be visualised but an ultrasound study did not reveal any infiltration. A dose of $500 \mathrm{cGy}$ was delivered to each eye in five fractions over 5 days. For 2 years the ocular findings did not change, but during the third year he developed a retinal detachment in the left eye which became phthisical. The right eye maintained some vision and its intraocular pressure was maintained within normal limits with betaxolol drops.

\section{Comment}

Juvenile xanthogranuloma is a rare and mostly benign skin disease of infants and young children of unknown aetiology. The cutaneous lesions are yellow and yellow-brown; they are elevated and sharply demarcated and have a diameter from 3 
to $10 \mathrm{~mm}$. Head and neck are the most common sites involved but lesions are also often present on the trunk and extremities. Eye lesions are very common. Involvement of organs other than skin and eyes is rather rare. Clinical ocular findings have been reported as isolated cases but the largest series were reported by Sanders ${ }^{3}$ and Zimmerman. ${ }^{4}$ Zimmerman reported that $85 \%$ of 28 cases involved infants younger than 1 year of age and $64 \%$ of 21 cases were infants 7 months old or younger. Our patients were all under 1 year of age. In four of them the ocular involvement was the first presenting symptom. In the other patient skin lesions and iris involvement occurred at the same time.

Juvenile xanthogranuloma has a tendency to affect the iris, but other ocular manifestations such as eyelid, ${ }^{5}$ and epibulbar lesions, corneal involvement, ${ }^{67}$ and orbital involvement have been described. ${ }^{89}$ Involvement of the optic nerve, disc, retina, and choroid have also been reported. ${ }^{10}$

Clinically iris involvement can present in different ways: as an asymptomatic localised or diffuse tumour of the iris with yellow brown discoloration and with prominent iris vessels, as a red eye with signs of uveitis, in many cases as a spontaneous hyphaema and, in more advanced cases, with severe secondary glaucoma. ${ }^{4}$

An asymptomatic iris mass should be differentiated from an amelanotic melanoma, iris leiomyoma, haemangioma, or lymphangioma.

The most frequent clinical finding in a xanthogranuloma of the iris is a hyphaema because the infiltration of the iris is often not noticed by the parents. However not every spontaneous hyphaema is caused by a juvenile xanthogranuloma. It may also occur in a medulloepithelioma, ${ }^{11}$ retinoblastoma, ${ }^{12}$ persistent primary hyperplastic vitreous, ${ }^{13}$ blood dyscrasias such as leukemia, ${ }^{14}$ is vascular malformations, ${ }^{16}$ retinoschisis, retrolental fibroplasia, and as a late effect of a trauma. ${ }^{17}$ In older children scurvy, purpura, severe iritis, and rubeosis may also cause an apparently spontaneous hyphaema. ${ }^{18}$ In our patients discoloration of the iris was the first ocular symptom in two patients, a hyphaema in two patients, and corneal haze owing to severe glaucoma was the first symptom in the fifth patient.

Ocular lesions of juvenile xanthogranuloma are usually unilateral but bilateral involvement has also been described. ${ }^{19}$ Except for patient 5 there was unilateral involvement in our patients.

A diagnosis should be established before starting any treatment. In the past eyes with iris nodules and spontaneous hyphaemas have occasionally been mistaken for malignancy and have been enucleated. ${ }^{3}$ In a patient with skin lesions the diagnosis is made after skin biopsy and histopathological examination. In isolated ocular lesions histopathological examination of the aqueous obtained at paracentesis with or without iris biopsy confirms the diagnosis. ${ }^{20}$ Iris biopsy however could be complicated by massive haemorrhage because of the highly vascularised tissue.

In three of our patients the diagnosis was made by histopathological examination of the aqueous or iris biopsy; in the other two biopsy of a skin lesion was performed. In the past many clinically diagnosed cases have been successfully treated without histological confirmation of skin or iris lesions..$^{21-23}$

Histopathological examination typically shows infiltration of the iris by histiocytes, many of them foamy. Nuclear morphology is bland, with no abnormal mitoses. Touton giant cells, the pathognomonic features of juvenile xanthogranuloma, may not be seen in small specimens, but the clinical presentation and characteristic morphology of the infiltrate allows the diagnosis to be made. Histopathologically, the important differential diagnosis is with embryonal rhabdomyosarcoma, but a good clinical history and negative immunostaining for desmin rules this out. The histiocytes of juvenile xanthogranuloma show positive immunostaining.

The therapy depends on the condition of the eye. Early treatment of iris involvement is mandatory because untreated it can lead to uncontrolled glaucoma, corneal blood staining, or amblyopia.

If a hyphaema or secondary glaucoma is not present, a therapeutic trial with topical steroids is suggested. ${ }^{21}$ Antiglaucoma therapy with acetazolamide can be added if necessary. ${ }^{22}$ This conservative management is justified because spontaneous regression of the ocular lesion might occur. An excisional biopsy of the lesion if smaller than one quadrant of the iris has been advocated in the past. ${ }^{24}$

Topical steroids, as in patients 1 and 4, may not prevent recurrent hyphaemas and glaucoma. Supplemental therapy with systemic steroids, ${ }^{2425}$ low dose radiotherapy (300-400 cGy), ${ }^{2326-28}$ or a combination of both ${ }^{19}$ might be necessary. Recently, successful treatment with one supplemental subconjunctival injection of steroids has been reported in a case with resistance to topical steroids. ${ }^{29}$ With only one supplemental injection of $2 \mathrm{ml}$ of dexamethasone solution $(4 \mathrm{mg} / \mathrm{ml})$ and betamethasone suspension $(6 \mathrm{mg} / \mathrm{ml})$ in a 50:50 mixture, there was no further bleeding and a reduction of size of the mass.

Long acting periocular steroid injection is a good alternative to systemic steroids to avoid their side effects. The most important side effects of prolonged use of topical steroids are cataract and glaucoma. The risk increases with the amount and duration of therapy.

Subconjunctival injections of $30 \mathrm{mg}$ methylprednisolone adjacent to the lesion were used in four of our five patients. They all presented early without evidence of glaucoma. Afterwards they were all treated with topical steroids. One patient did well after one injection; two patients needed two injections and the other patient three injections. There was regression of the tumour in all cases without recurrence of hyphaemas. None of our patients developed cataract or glaucoma. The last patient presented late with cloudy corneas owing to the secondary glaucoma. He had several antiglaucomatous operations. In this patient low dose radiotherapy was necessary to control further infiltration of the iris by the xanthogranuloma.

From those five cases we can conclude that early recognition of the condition before glau- 
coma is present, is necessary for a successful outcome by treatment with subconjunctival injections of steroids. Systemic steroids or low dose irradiation should be considered if periocular steroids are ineffective. Low dose irradiation (300-400 cGy) in fractions of $50 \mathrm{cGy}$ over at least 2 weeks has been advocated ${ }^{28}$ in order to prevent a sometimes uncontrollable secondary glaucoma. With this very low dose irradiation no cataract formation was reported. In more resistent cases cataractogenic doses of $x$ ray may be required, but cataract is preferred to severe glaucoma and loss of the eye. ${ }^{3}$

1 Blank H, Eglich PG, Beerman H. Nevoxanthoendothelioma with ocular involvement. Pediatrics 1949; 4: 349-54.

2 Maumenee AE. Ocular lesions of nevoxanthoendotheliom (infantile xanthoma disseminatum). Trans Am Acad Ophthalmol.Otolaryngol 1956; 60: 401-5.

3 Sanders TE. Intraocular xanthogranuloma (nevoxanthogranuloma). A survey of 20 cases. Trans Am Ophthalmol Soc granuloma). A surv

4 Zimmerman LE. Ocular lesions of juvenile xanthogranuloma. Nevoxanthoendothelioma. Trans Am Acad Ophthalmol Otolaryngol 1965; 69: 412-39.

5 Fleischmajer R, Hyman AB. Juvenile giant cell granuloma (nevoxanthoendothelioma). In: Fleischmajer R, ed The dyslipidosis. Springfield, IL: Thomas, 1960: Chapter 18, 329-72.

6 Cogan DG, Kuwabara T, Park D. Epibulbar nevoxanthoendothelioma. Arch Ophthalmol 1958; 59: 717-21.

7 Lewis JR,Drummond GT, Mielke BW, Hassard DTR, Astle WF. Juvenile xanthogranuloma of the corneoscleral limbus. Can f Ophthalmol 1990; 25: 351-4.

8 Staple TW, McAlister WH, Sanders TE, Miller JE. Juvenile xanthogranuloma of the orbit: report of a case with bone xanthogranuloma of the orbit: report of a case

9 Shields CL, Shields JA, Buchanon HW. Solitary orbital involvement with juvenile xanthogranuloma. Arch Ophthalmol 1990; 108: 1587-9.

10 Wertz FD, Zimmerman LE, McKeown CA, Croxatto JO Whitmore PV, LaPiana FG. Juvenile xanthogranuloma of the optic nerve, disc, retina, and choroid. Ophthalmology 1982; 89: 1331-5.

11 Zimmerman LE, Broughton WL. A clinicopathologic and follow-up study of 56 intraocular medulloepitheliomas. In: Jakobiec FA, ed. Ocular and adnexal tumors. Birmingham, Jakobiec FA, ed. Ocular and adnexal tumors. Birmingham,

12 Appelboom T, Durso F. Retinoblastoma presenting as a total hyphema. Ann Ophthalmol 1985; 17: 508-10.

13 Reese AB. Persistent hyperplastic primary vitreous. Am 7 Ophthalmol 1955; 40: 317-31.

14 Rosenthal AR. Ocular manifestations of leukaemia: a review. Ophthalmology 1983; 90: 899-905.

15 Tabbara KF, Beckstead JH. Acute promonocytic leukaemia with ocular involvement. Arch Ophthalmol 1980; 98. 1055-9.

16 Crompton JL, Taylor D. Ocular lesions in the blue rubber bleb naevus syndrome. Brf Ophthalmol 1981; 65: 133-7.

17 Howard GM. Spontaneous hyphaema in infancy and childhood. Arch Ophthalmol 1962; 68: 615-20.

18 Doggart JH. Spontaneous hyphaema. 16th Council Ophthalmol Acta 1950; 1: 450-5.

19 Hadden OB. Bilateral juvenile xanthogranuloma of the iris. Br f Ophthalmol 1975; 59: 699-702.

20 Schwartz LW, Rodrigues MM, Hallett JW. Juvenile xanthogranuloma diagnosed by paracentesis. Am $\mathcal{f}$ Ophthalmol 1974; 77: 243-6.

21 Clements DB. Juvenile xanthogranuloma treated with local steroids. BrF Ophthalmol 1966; 50: 663-5.

22 Stern SD, Arenberg IK. Infantile nevoxanthoendothelioma of the iris treated with topical steroids and antiglaucoma therapy $f$ Pediatr Ophthalmol Strabismus 1970; 7: 100-2

23 Cadera W, Silver MM, Burt L. Juvenile xanthogranuloma. Can f Ophthalmol 1983; 18: 169-74.

24 Gass JDM. Management of juvenile xanthogranuloma of the iris. Arch Ophthalmol 1964; 71: 344-7.

25 Harley RD, Romayananda N, Chan GH. Juvenile xanthogranuloma. F Pediatr Ophthalmol Strabismus 1982; 19: 33-9.

26 Thieme R, Lukassek B, Keinert K. Zum Problem des juvenilen Xanthogranuloms der vorderen Uvea. Klin Monatsbl Augenheilkd 1980; 176: 893-8.

27 MacLeod PM. Case report: juvenile xanthogranuloma of the iris managed with superficial radiotherapy. Clin Radiol iris managed with superficial radiotherapy. Clin Radiol

28 Müller RP, Busse H. Strahlentherapie bei juvenilem Xanthogranulom der Iris. Klin Monatsbl Augenheilkd 1986; 189: $15-8$

29 Treacy KW, Letson RD, Summers CG. Subconjunctival steroid in the management of juvenile xanthogranuloma: a case report. 7 Pediatr Ophthalmol Strabismus 1990; 27: $126-8$ 